\title{
Representações sociais de policiais civis sobre profissionalização
}

ALEXANDRE SANT'ANA DE BRITO* E LÍDIO DE SOUZA**

\section{Introdução}

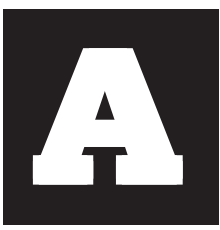

trajetória, a função, a legitimidade e mesmo a origem do aparelho policial estão intrinsecamente ligados à organização dos Estados-Nação. A polícia se insere no cerne da governabilidade do Estado por meio da produção de tecnologias que as sujeitam à ação dos grupos sociais e dos indivíduos ao mesmo universo de leis em um mesmo território nacional (SANTOS, 1997).

Na concepção de Weber (1968), o Estado Moderno não deve ser definido por seus fins, mas por algo que o faz peculiar em relação aos outros, isto é, o fato de ser

[...] um agrupamento de dominação que apresenta caráter institucional e que procurou (com êxito) monopolizar, nos limites de um território, a violência física legítima como instrumento de domínio e que, tendo esse objetivo, reuniu nas mãos dos dirigentes os meios materiais de gestão. Equivale isso a dizer que o Estado moderno expropriou todos os funcionários que, segundo o princípio dos 'Estados' dispunham outrora, por direito próprio, de meios de gestão, substituindo-se a tais funcionários, inclusive no topo da hierarquia (p.62).

\footnotetext{
* Mestrando em Psicologia pelo Programa de Pós-Graduação em Psicologia da Universidade Federal do Espírito Santo.

** Professor-Doutor do Programa de Pós-Graduação em Psicologia da Universidade Federal do Espírito Santo.
} 
Foi a partir do final do século XVII que o Estado passou a exercer a sua governabilidade política por meio de dois dispositivos: a razão de Estado e a razão de polícia.

A razão de Estado refere-se aos "[...] interesses vitais de ordem estabelecida..." (WEBER, 1968, p. 79), ou seja, à perpetuação do próprio Estado, à sua capacidade de auto-imposição diante de outros Estados e de regulação de sua realidade social interna, em termos materiais e simbólicos. Já a razão de polícia compreende

[...] a justiça, as finanças e o exército; a polícia englobava tudo, [...] [e] o objeto específico da polícia consistia na 'sociedade' e os homens enquanto que seres sociais, indivíduos plenos de todas suas relações sociais. A 'teoria da polícia' especificava a natureza dos objetos, os domínios de competência, os objetivos, os instrumentos da atividade racional dos organismos estatais (SANTOS, 1997, p. 157-158).

Com a delimitação de um território, a institucionalização de um idioma, de leis soberanas e de uma cosmologia comum, ou seja, da construção de uma nacionalidade, esses dispositivos passaram a agir diretamente sobre os problemas econômicos, políticos e sociais. O poder do Estado, encarnado nas polícias entendidas como a totalidade das intervenções estatais, controlava e dirigia a população.

A governabilidade estatal se fez completa (SANTOS, 1997) com a estruturação da instituição policial como força disciplinadora e disciplinar, mantenedora do poder do Estado e, concomitantemente, da segurança e coordenação das ações da população, aliada à delegação ao exército da proteção das fronteiras entre os Estados-Nação. A polícia moderna, segundo Santos (1997) e Bretas (1997), pode ser caracterizada pela existência de três modelos: o francês; o inglês e o dos países periféricos.

A polícia, na França, foi constituída por ocasião da assinatura do "ato de nascimento da polícia", por Luís XIV, no século XVII, com as finalidades 
de proteger a cidade contra os delinqüentes e os criminosos, os cidadãos contra as doenças e as epidemias, bem como cuidar de sua subsistência. Entretanto, o modelo francês de polícia propriamente dito, é oriundo do período posterior à Revolução Francesa, por ocasião do Código do Brumário ano IV. Embora seguisse o lema liberdade, igualdade e fraternidade, em nome da ordem pública, caracterizou-se por ser centralizadora e estatal, indicando sua íntima relação com a formação do Estado.

O modelo inglês de polícia acrescentou às características do modelo francês a aproximação da instituição com a sociedade, lançando mão do consenso como forma de se legitimar como "[...] tecnologia de poder que realiza a governabilidade do Estado-Nação" (SANTOS, 1997, p. 161). A diminuição das desordens, a cooperação voluntária da população, o uso mínimo da força física e a prestação adequada de serviços a toda a sociedade destacam-se entre as principais características desse modelo.

Por fim, o modelo dos países periféricos se refere à inclusão da violência ilegítima e das práticas extrajudiciais nos modelos policiais francês e inglês, ambos característicos dos países centrais.

As características contidas nos modelos de polícia não são excludentes, de maneira que os estudos a respeito da polícia, ou de policiais, deveriam flexibilizá-las, evitando uma falaciosa valorização dos países centrais. Na verdade, o que se pretende é problematizar a complexidade de motivações que levam um policial a agir violentamente (MENANDRO, 1979), e compreender melhor como "[...] em certos países a polícia responde a pressões da sociedade e de governos para respeitar certos limites [...], [enquanto] em outros pode-se dizer que o desvio é a norma" (BRETAS, 1997, p. 82).

Através do estudo da história social brasileira, podemos verificar a permanência de certas práticas socioeconômicas, políticas e sociais, que caracterizam um etos, um mecanismo clientelista, oligarquista patrimonial que, praticamente sem rupturas, orienta as relações sociais. Desde a colo- 
nização até os tempos atuais, as forças ${ }^{1}$ políticas e sociais conservadoras brasileiras têm conseguido fazer do Estado brasileiro e da polícia ${ }^{2}$, seus servidores, açambarcando a soberania das leis e a vivência da cidadania (MARTINS, 1994). Esta perspectiva de análise permite revelar a indelével contribuição de determinados segmentos sociais para a constituição das práticas violentas, ilegais, ilegítimas e não-profissionais da polícia civil brasileira (MESQUITA NETO, 1999) e, mais especificamente, da capixaba.

No caso da França, da Inglaterra e dos EUA, a violência emerge como luta antiinstitucional das massas contra um Estado que, muitas vezes, não cumpre integralmente suas obrigações sociais. Violência que é intensificada pela constante imigração de estrangeiros interessados em melhorar a sua condição de vida, o que desencadeia conflitos motivados pela xenofobia. Já no Brasil, os confrontos decorrem da ausência da ação mediadora do Estado nas relações entre os indivíduos e os grupos, caracterizando conflitos de ordem criminal e não antiinstitucional. Esses confrontos são mais visíveis nas favelas onde a ausência da mediação estatal é mais evidente e onde, freqüentemente, a população resolve os conflitos baseada em princípios próprios, à revelia das leis (MACÉ, 1999).

A banalização da injustiça social tornou-se uma poderosa ferramenta do capitalismo. A despeito das contradições e aviltações que impinge às populações, o capitalismo, através de uma magia naturalizante, faz com que o mal social se torne banal, e os indivíduos se vejam pelo prisma do darwinismo econômico, ratificando a condição de outgroup das massas despreparadas para o mundo globalizado. Estamos diante do paradoxo da modernidade: suavizamos os nossos costumes e nos tornamos seres de larga compaixão, legamos ao Estado o poder legítimo do uso da violência, todavia os nossos bons sentimentos em relação a outrem não implicam

1 Referimo-nos a "forças", pois não excluímos de maneira alguma a participação efetiva dos vários setores sociais brasileiros nesse processo.

2 A despeito de existirem "polícias brasileiras", foi empregado o termo no singular, para enfatizar a polícia civil, representada pelos investigadores e agentes de polícia abordados neste trabalho. 
nossa ativa intervenção em nome de sua felicidade. Estamos humanizados nos sentimentos, mas refratários nas atitudes (LIPOVETSKY, 1986).

Tomemos o trinômio Estado, polícia e população como referencial de estudo da violência policial no Brasil. As práticas violentas da polícia são interpretadas de modo ambíguo pela população. Se, por um lado, ela solicita, autoriza e legitima tais modos de ação, freqüentemente para a solução de seus problemas pessoais, por outro lado, é capaz de se indignar e denunciá-las, quando delas se torna vítima. Destacamos, portanto, que o apoio da população às práticas extrajudiciais se constitui em um importante fator para a sua legitimação, embora não seja o único, pois

O apoio que uma parte da comunidade confere às ações extrajudiciais da polícia constitui um questionamento ao estado de direito muito superior ao representado pela ação extrajudicial propriamente dita. A polícia pode exceder-se ou atuar fora das atribuições que a lei lhe outorga, mas isso não representaria um risco tão grande para a democracia e a legitimidade se não tivesse $O$ apoio dos cidadãos (BRICEÑO-LEON; CARNEIRO; CRUZ, 1999, p. 126).

A principal razão do estímulo às ações extrajudiciais, segundo BriceñoLeón, Carneiro e Cruz (1999), seria o medo da violência e da delinqüência, decorrente do acentuado crescimento das taxas de homicídios na América Latina desde o início da década de 1980. As pessoas, por medo de serem novas vítimas da própria violência, solicitam-na como eficaz arma contra os criminosos. Outra razão seria a vingança, fato inteligível se considerarmos a ineficácia do Estado brasileiro na mediação social (MACÉ, 1999). Acrescentamos a essas observações o fato de a polícia brasileira, desde a sua formação, ter um caráter de combate aos criminosos, em geral os originários das classes baixas, para proteção das elites políticas e econômicas (MARTINS, 1994; CALLIGARIS, 1998; BRETAS, 1997), as quais, através do clientelismo político, direcionam as ações do Estado e da polícia. 
Devemos, entretanto, assinalar que setores das classes baixas, vítimas do processo de exclusão social, lançam mão, similarmente aos segmentos mais abastados, do mesmo clientelismo para a solução de seus problemas. Sob a forma do apadrinhamento, usam a proximidade que têm de pessoas pertencentes às instituições policiais, para obter apoio e proteção (MENANDRO; SOUZA, 1996; BRETAS; PONCIONI, 1999). A consideração do etos brasileiro parece ser necessária para o entendimento deste processo (MARTINS, 1994).

Em função desse etos, tornou-se, para os brasileiros, complexa a definição de limites claros entre os espaços público e privado, fato claramente nocivo à concretização do Estado de Direito, mas que, uma vez superado, poderá representar uma via eficaz para a consolidação da democracia (WIEVIORKA, 1997):

Se a violência, mesmo não política, infra ou metapolítica, remete ao ponto central onde se situa a política, isso significa que ela surge e se desenvolve através das carências e dos limites do jogo político, e que ela pode também, se as condições políticas estiverem reunidas, regredir ou desaparecer em função de um tratamento institucional das demandas que ela vem traduzir (p. 199).

A peculiaridade da história brasileira não é a corrupção praticada, mas sim, a mediação conservadora, clientelista e oligárquica patrimonial que bloqueia o avanço das práticas sociais e políticas em novas direções. Os atos de corrupção, da mesma forma que a ilegalidade e a ilegitimidade no uso da força policial, não são práticas restritas aos países periféricos, o que pode ser exemplificado nos confrontos que resultaram na morte de um ativista italiano, pela polícia de seu país, durante uma manifestação contrária ao encontro do G-8, em setembro de 2001. A nossa peculiaridade é a dificuldade em vermos a corrupção nos pequenos atos do dia a dia, bem como o fato de não termos transformado de modo significativo a 
nossa estrutura ideológico-política no desenvolvimento de nossa história republicana. Noutras palavras,

[...] As recentes denúncias de corrupção, que poderiam ter levado, mais do que qualquer coisa, a uma revisão profunda do sistema político brasileiro, mais do que exclusivamente do Estado brasileiro, apenas revelaram como a sociedade inteira está profundamente envolvida naquilo que a constrange e que denuncia. A denúncia da corrupção serviu exatamente para mostrar a natureza viciosa do sistema político (MARTINS, 1994, p. 13).

Assim como as sociedades são dinâmicas, a forma como lidam com os seus problemas internos e externos, as concepções sobre violência e o seu tratamento como práticas sociais, também são dinâmicos. Segundo Porto (2000), isso se deve, principalmente, às mudanças nos valores sociais decorrentes da quebra da unidade social, em direção à multiplicidade de valores que passaram a matizar a composição do tecido social, que resultaram na ausência de referenciais socioculturais para o gerenciamento dos grupos e indivíduos. Realidade semelhante já tinha sido apontada por Moscovici (1978) quando da elaboração da Teoria das Representações Sociais (TRS's), que tem como foco principal as sociedades modernas e o seu contexto urbano, caracterizado por múltiplos objetos sociais de natureza altamente dinâmica e instável (WAGNER, 1998; ABRIC, 1998; SÁ, 1998; JOVCHELOVITCH, 1998).

Ao tratar da violência policial, Menandro (1979) se contrapõe veementemente à idéia de que ela estaria diretamente relacionada aos traços psicológicos dos policiais recalcitrantes, o que poderia ser resolvido pela melhor seleção dos ingressos, e defende a idéia de que "[...] os determinantes da agressão humana encontram-se basicamente nas práticas sociais e não em características internas do ser humano" (p. 142). Esta posição teórica é ratificada por trabalhos que foram desenvolvidos no ES junto aos policiais 
militares (MENANDRO; SOUZA, 1996) e policiais civis (CAVASSANI, 1998; BOURGUIGNON, 1996), apontando esses trabalhos inadequação na formação profissional (formação e aprimoramento) e nas condições de infraestrutura, além das ambigüidades que regulam a relação polícia/sociedade.

A perspectiva psicossocial utilizada nesses estudos reforça o entendimento de que a psicologia é eminentemente social e exige que se considere o inequívoco caráter dialógico das produções humanas (LANE, 1991), na qual a natureza única de cada indivíduo está sempre "referida [...] ao sistema de significações que sua sociedade lhe possibilitou" (NOVO, 1996, p. 21). Se a violência policial se inscreve nas relações de poder presentes no tecido social, é através de estudos psicossociais e históricos sobre como ela é concebida, praticada e controlada, que poderemos, mais adequadamente, identificar os principais fatores que levaram à constituição e manutenção do sistema policial brasileiro e capixaba.

No decurso de sua história, a Polícia Civil do ES assumiu atribuições de Guarda Nacional, de serviço de trânsito, de polícia marítima e aérea, e até 1960, de polícia judiciária. Durante o regime militar, mais precisamente em 1967, foi criada a Secretaria de Segurança Pública do ES, atribuindo à Polícia Civil o exclusivo papel de polícia judiciária, congregando-a ao campo da repressão política e ideológica pelo DOPS. Em 1975, passou a ser denominada Superintendência Geral de Polícia Civil (BOURGUIGNON, 1996).

Segundo Bourguignon (1996), entre os fatores que estimulam o ingresso na instituição policial civil estão: a atração pela imagem do policial divulgada pela mídia, principalmente filmes; necessidade de sobrevivência; carga horária considerada baixa; histórico familiar que inclui a existência de parentes policiais; carreira militar antecedente; vocação. Menandro e Souza (1996) apontam os principais motivos alegados por policiais militares para o ingresso na carreira: $48 \%$ disseram ter ingressado pelo gosto pelo militarismo e/ou vocação; $26 \%$ por causa do desemprego e $43 \%$ tinham parentes na corporação. Cavassani (1998), em pesquisa junto a policiais civis, identi- 
ficou como mais importantes as seguintes motivações ${ }^{3}$ : a importância e utilidade social da profissão; atração pela idéia de autoridade; necessidade de emprego e as vantagens da carreira.

Como pode ser notado, trata-se de uma constelação de razões para o ingresso dos civis na polícia. Mais do que espaço de realização profissional, a polícia se tornou um emprego como outro qualquer. Com a exigência dos concursos para o ingresso, os policiais podem desfrutar da estabilidade no emprego e se distanciar do estigma de desempregados, categoria marginal na ordem capitalista (Dejours, 1999).

Entretanto o ingresso na carreira não livra o policial dos estigmas. Considerando a idéia de que policial bom é policial violento, constantemente ratificada pela própria sociedade (MENANDRO; SOUZA, 1996; BRICENÕLEÓN; CARNEIRO; CRUZ, 1999; CAVASSANI, 1998), quando alguns sujeitos se opõem ao uso ilegal da violência contra os suspeitos e/ou detentos, são alijados do grupo, recebendo o sinal negativo de covardes e poucos confiáveis (CAVASSANI, 1998; BOURGUIGNON, 1996).

Partindo do entendimento de que as condições do trabalho podem causar o sofrimento, a morte, a loucura e a banalização das injustiças, Dejours (1999) aponta a existência de um mecanismo de defesa, de uma estratégia defensiva do trabalhador diante das situações aviltantes do dia-a-dia de seu ofício, de forma a sobreviver à realidade com a qual muitas vezes compactua e colabora. Bourguignon (1996) apresenta, no caso dos policiais civis do ES, as principais expressões dessa estratégia: recusar-se a fazer uso de colete protetor, mesmo nas poucas situações em que estão disponíveis; aceitar as regras do plantão; usar bebidas alcoólicas, e, novamente, a rejeição dessas regras representará a exclusão do indivíduo do grupo, sendo ele estigmatizado como covarde e de pouca confiança.

\footnotetext{
${ }^{3}$ Em seu trabalho, a autora buscou analisar a possível relação entre o adoecimento policial e as razões de ingresso na instituição. Foi observado que os policiais que ingressaram por razões sociais ("prestar ajuda à sociedade") estavam mais propensos ao adoecimento do que aqueles que o fizeram por gostar do perfil da profissão e interessados no status/poder.
} 
Portanto, é crucial para as intervenções que objetivam a otimização e a democratização do trabalho policial, a consideração de suas representações sociais sobre sua própria condição profissional, bem como em relação ao complexo conjunto de relações com a sociedade, a instituição policial e o Estado. É fundamental considerarem-se as múltiplas injunções que obstaculizam a execução de suas funções profissionais num universo ambíguo, onde se fala na lei, mas não se pode cumpri-la por causa das condições de infra-estrutura, das deficiências na profissionalização, da solicitude de ações extrajudiciais e do recurso à violência ilegítima.

Menandro e Souza (1996) apontam a importância dessa realidade para o desenvolvimento das percepções dos policiais, para a solução dos problemas de segurança pública e para uma compreensão melhor da relação polícia/sociedade: o policial vê no know-how a pedra de toque para a solução de tais problemas, mantendo uma situação de exclusão social baseada em estereótipos sobre criminosos e bons cidadãos e, em decorrência, maior seletividade em suas ações e individualização na tomada de decisões. Cavassani (1998), por seu turno, continuou avançando no entendimento deste complexo quadro, identificando-o como um espaço fecundo para as práticas excludentes e violentas. Os policiais podem aderir às práticas violentas existentes na instituição, possibilitando a integração grupal, mas podem também resistir a elas, embora com maior suscetibilidade ao adoecimento.

Esses trabalhos ratificam a importância dos estudos psicossociais para o melhor entendimento, não só das ações das agências policiais, mas também da sociedade como um todo, haja vista que,

Acompanhar o dia a dia desses trabalhadores que vivem no viés [sic] da marginalidade da sociedade, que têm ordens internas rígidas que na prática são impossíveis de serem cumpridas, que exercem suas atividades em condições de risco e, ao mesmo tempo, respeitar suas formas de adaptação carregadas de sofrimento, 
medo e insegurança, nos fez desenvolver uma nova consciência crítica em relação à Polícia Civil (BOURGUIGNON, 1996, p. 112).

Esta visão ampla e crítica sobre práticas e comportamentos é sine qua non para a quebra do mito da não violência do brasileiro (CHAUÍ, 1980), retroalimentado por sua forma particular de produção histórica lenta (MARTINS, 1994), fruto de práticas sociais conservadoras interiorizadas, sustentadas e, até o momento de nossa história, presentes e representadas pelo clientelismo político e oligarquismo patrimonial. Valemos pelo que temos e pelo nosso status, ou pelo status daqueles aos quais estamos subordinados.

O Espírito Santo, dessa forma, insere-se no contexto nacional/mundial relacionado à existência de uma cultura de incentivo à violência (BRETAS, 1997; MACÉ, 1999; BRETAS; PONCIONI, 1999), no nacional, onde é freqüente a solicitação de práticas extrajudiciais e de violência ilegítima no trato com a criminalidade (MESQUITA NETO, 1999; BRETAS; PONCIONI, 1999; MACÉ, 1999; SANTOS, 1997; CARNEIRO, 1999), e em sua realidade social cotidiana, onde são elaboradas representações sociais, retroalimentadas pelos níveis anteriores, que sustentam um etos, uma identidade e, por conseguinte, papéis sociais que naturalizam, banalizam e incrementam a violência social.

Acreditamos que, através do estudo das representações sociais de policiais civis/ES em relação ao seu papel social, às dificuldades que têm enfrentado no cumprimento de seu dever, ao modo como avaliam que deveriam profissionalizar-se e ao modo como analisam as relações entre a instituição policial e o Estado, poderemos contribuir para a avaliação de como o complexo quadro no qual concretamente se realizam os trabalhos da polícia pode refletir-se no processo de democratização do Estado no Espírito Santo.

As representações sociais não são um espelho da realidade, mas a realidade apreendida, reconstruída, aproximada e compartilhada pelo gru- 
po (JOVCHELOVITCH, 1998; ABRIC, 1998), e desempenham as seguintes funções: permitem a compreensão e explicação da realidade; definem a identidade e a especificidade dos grupos; orientam as práticas sociais; justificam, a posteriori, as decisões tomadas nas variadas conjunturas sociais (ABRIC, 1998).

A Representação de Profissionalização se refere, portanto, às percepções que os sujeitos têm de sua profissionalização, do seu papel social, e como a íntima relação de seu trabalho com as esferas institucional e política pode auxiliar ou obstruir a execução de suas tarefas e funções. Em última instância, o presente estudo busca analisar quanto as suas percepções, forjadas na confluência de forças políticas, sociais e econômicas, podem contribuir para a concretização dos ideais democráticos na sociedade capixaba.

Uma vez que a Representação de Profissionalização é produzida e transformada nas práticas diárias dos policiais civis/ES, pari passu à manutenção de sua identidade social, destacamos a função identitária das representações sociais, pois, a proximidade entre o objeto em questão e os sujeitos, isto é, "[...] a representação de um grupo social pelo próprio grupo - fazendo, pois com que o sujeito e objeto da representação coincidam..." (SÁ, 1998, p. 59), é aqui presumida.

Mais do que a existência de meras opiniões sobre assuntos e atitudes isoladas pelos grupos, as representações (esquematismos psicossociais e práticos), no entendimento de Moscovici (1978) e Sá (1993), são verdadeiras teorias do senso-comum presentes nas informalidades do cotidiano, por exemplo, durante as refeições familiares, nos pontos de ônibus, nos supermercados, nos bares e boates, enfim, onde quer que se pare e dialogue, isto é, que se "jogue conversa fora".

Se o conceito de profissionalização está relacionado ao processo de preparação e de obtenção de conhecimentos pertinentes a um dado ofício ou profissão, principalmente no caso policial, certos cuidados precisam ser tomados, de forma a esses profissionais poderem se desenvolver, concomitantemente, de forma corporativa - para também poderem fazer 
valer o seu saber profissional diante das opiniões de grupos externos (MESQUITA NETO, 1999) e, em termos de uma consciência ético-política (SAWAIA, 1999), para não supervalorizarem a sua condição de servidores públicos especiais (direito legal de uso da violência legítima), em detrimento do serviço social que deveriam prestar, em prol da democracia e dos direitos humanos, contra a reprodução da tradicional cultura de violência há muito difundida no País (NOVO, 1996).

Adotaremos aqui o conceito de profissionalização defendido por Mesquita Neto (1999) o qual

[...] sugere que a violência policial é um comportamento antiprofissional, não-profissional ou pouco profissional, antes de sugerir que a violência policial é um comportamento ilegal, ilegítimo ou irregular por parte de policiais envolvidos em atos de violência. Esta concepção sugere a necessidade da profissionalização da polícia e da melhoria da formação e aperfeiçoamento profissional dos policiais antes de sugerir a necessidade de uma punição dos policiais envolvidos em atos de violência como forma de controlar a violência policial. Portanto, não produz automaticamente uma reação negativa por parte dos policiais [...] (p. 136).

\section{Captando o conteúdo das representações}

Objetivando captar informações sobre o conteúdo das representações sociais, elaborou-se um questionário semi-estruturado que focalizou os seguintes tópicos de interesse dos sujeitos: percepção pessoal, incluindo os seus valores humanos e ético-profissionais, condições físicas, intelectuais e da saúde mental; percepção institucional, em relação às oportunidades que Ihes são oferecidas de ascensão profissional, infra-estrutura da polícia para a profissionalização e cumprimento das responsabilidades, relações internas à 
instituição, salário e benefícios trabalhistas; percepção política, relativa às relações da polícia com o poder político, notadamente com o Poder Executivo. Os questionários foram aplicados a 135 policiais civis lotados na região da Grande Vitória, exercendo as funções de investigadores e agentes de polícia, ${ }^{4}$ categorias que lidam diretamente com o universo prático do trabaIho policial (guarda e transporte de presos; busca e apreensão de objetos e pessoas; intervenções em situações de risco de vida iminente).

Em relação às representações dos sujeitos sobre a esfera política (Estado), notamos a existência de percepções negativas em relação aos investimentos na segurança pública, na polícia civil e em relação à interferência política no trabalho policial. Os dados revelaram a inadequação da infraestrutura da instituição policial em relação ao seu setor pedagógico (Acadepol) e à baixa qualidade dos seus trabalhos. Os policiais indicaram a pouca quantidade e baixa freqüência de oferta dos cursos (entre regular e péssimo com 57,9\%); a inadequação dos critérios utilizados para seleção dos alunos (entre pouco adequado e inadequado com 62\%); pequeno contingente de policiais para o bom funcionamento da instituição, por ocasião da ausência daqueles designados para fazer os cursos (40\%). Além disso, indicaram também a insuficiente duração dos cursos (entre pouco adequado e inadequado, com $77 \%$ ) e, principalmente, os problemas relacionados ao pagamento dos salários. ${ }^{5}$

No tocante às relações estabelecidas entre a política (principalmente com o Executivo) e a polícia, as percepções dos sujeitos indicam que a polícia age em primeiro lugar para atender aos interesses das classes políticas dominantes e dos delegados (51,9\%). Assim, quando sugerem que a

\footnotetext{
4 Ainda que ambas as categorias tenham, em tese, funções distintas, sendo delegada aos investigadores a função de levantamento de informações a respeito dos delitos e, aos agentes, a guarda de presos, observa-se, notadamente desde fins de 1998, após a assunção, pela polícia militar da responsabilidade dos principais complexos penitenciários do ES, que ambas as categorias têm desenvolvido as mesmas atividades.

5 Algumas assertivas também revelam a insatisfação dos sujeitos com os seus vencimentos, a citar: "todos os cursos deveriam possibilitar ascensão profissional" (40\%); "Deveriam investir principalmente na melhoria dos salários e benefícios de trabalho (jornada de trabalho, gratificações, folgas, etc." $(48,9 \%)$ ).
} 
polícia deveria aproximar-se do Judiciário e se desvincular administrativamente do Executivo (40\%), sinalizam que os interesses políticos de classe interferem na qualidade, no teor, e na efetividade de suas ações, em detrimento de suas responsabilidades legais e sociais em relação à democracia.

Em relação à percepção dos sujeitos sobre a esfera institucional, em termos das oportunidades que lhes são oferecidas, de ascensão profissional, da qualidade dos equipamentos para o trabalho e para sua formação/ atualização, do respeito da chefia, e da adequação dos horários, das rotinas de trabalho, do salário e dos benefícios, as representações sociais permaneceram negativas.

A polícia, em razão dos inadequados e insuficientes investimentos do Estado (79,6\% entre pouco adequados e inadequados), não tem podido oferecer as condições necessárias para a formação e o aprimoramento profissional dos policiais (deficiências da academia de polícia, horários incompatíveis entre cursos e jornada de trabalho, equipamentos inadequados), além da falta de apoio psicológico (34,1\%), fundamental devido à inerente carga de estresse da função policial.

Além disso, verificamos que a concepção dos policiais sobre as relações internas à instituição também é negativa e fragmentada gerando um clima de desconfiança entre os vários setores da instituição, fato reforçado pela forte concorrência para que se consiga a ascensão profissional. Esta observação ratifica a análise de Bretas e Poncioni (1999), em relação à sonegação de informação entre os policiais, pois "[...] É a partir de seu conhecimento que o policial se torna poderoso e indispensável, construindo o seu sucesso na carreira. Fazer circular a informação é perder uma parte significativa de seu capital simbólico" (p. 152).

Em relação à percepção sobre a esfera pessoal, a qual leva em conta os valores humanos e ético-profissionais, as condições físicas, intelectuais e de saúde mental dos policiais pudemos, mais propriamente, verificar as representações sociais da profissionalização, dado o fato de ser nesta esfera que eles revelam por que desejam a profissionalização. 
Em relação a essa esfera, notamos claramente que o interesse na ascensão profissional ${ }^{6}$ decorre principalmente da expectativa de ganho salarial (via Acadepol, ESESP e outras instituições que ministram cursos relacionados à Segurança Pública), e não de motivações relacionadas à responsabilidade e relevância social da profissão. Entretanto, apesar do interesse prioritário se relacionar à progressão funcional e ao aumento salarial, a profissionalização à qual querem submeter-se se refere à aquisição de conteúdos de ordem técnico-combativa, destacando-se os seguintes cursos: Armamento e tiro; Investigação Policial; Defesa Pessoal; Noções de Direito, e Relações Humanas/Relações Interpessoais? .

Uma vez que são cidadãos-policiais (MENANDRO; SOUZA, 1996), percebemos que, apesar de indicarem problemas existentes na instituição, sugeriram-nos a existência de estratégias defensivas (BOURGUIGNON, 1996; DEJOURS, 1999) que os fazem protegê-la. Em primeiro lugar, entendemos que a protegem porque é através dela que garantem os seus proventos e a subsistência familiar. Em segundo lugar, devido à inadequada mediação estatal característica dos países periféricos (MACÉ, 1999), agravadas no Brasil devido à existência de um etos clientelista e oligárquico (MARTINS, 1994), os policiais podem lançar mão da autoridade e do poder institucional para se protegerem, inclusive fisicamente. Por fim, em termos propriamente simbólicos, defendem-se do sofrimento ético-político, que

\footnotetext{
6 Tanto na função de investigador quanto na de agente de polícia é prevista a ascensão profissional seguindo o seguinte critério: os recém-integrados à instituição são policiais de primeira categoria e, contados dois anos após o cumprimento de estágio probatório (atualmente de três anos), é viabilizado para o policial o direito de concorrer à mudança para a segunda categoria, implicando ganho salarial. Por fim, após dois anos, já na segunda categoria, e tendo freqüentado o Curso de Aprimoramento Profissional da Acadepol, ele novamente estará apto a concorrer à terceira categoria. Nessa corrida pela ascensão profissional, todo e qualquer curso relacionado à segurança pública conta no aumento de pontos de cada indivíduo, aumentando-lhe as chances de ascender profissionalmente.

7 O curso de relações interpessoais tem uma vasta gama de subitens deveras positivos ao bom relacionamento polícia/ comunidade, entre os quais: empatia, ética policial (Estatuto do Policial Civil); motivação e liderança, todavia, com clara ênfase no aspecto da liderança e respeito às leis internas à instituição policial. Já o curso de direitos humanos destaca a evolução histórica do conceito, as condições socioculturais e econômicas, a Organização das Nações Unidas e de suas instituições e os instrumentos de proteção do cidadão contra os excessos do Estado. Possivelmente, em função da pouca freqüência de oferta dos cursos, aliado à sua baixa carga horária, é possível que os conteúdos dos cursos de "relações interpessoais" e "direitos humanos" se confundam, dada a similaridade de conteúdo sugerida pelo título de ambas as disciplinas. Esse fato pode justificar a semelhança percentual entre ambos.
} 
[...] retrata a vivência cotidiana das questões sociais dominantes em cada época histórica, especialmente da que surge da situação social de ser tratado como inferior, subalterno, sem valor, apêndice inútil da sociedade (SAWAIA, 1999, p. 104).

\section{Considerações finais}

As representações sociais vistas como "geradores de tomada de posição" e não definidoras de posição (SÁ, 1998), possibilitou-nos duas observações: a primeira em relação à natureza dos comportamentos humanos, que segundo Morin (1998), são de ordem complexa, originados e produtores de elementos antropológicos-mitológicos, psicossociológicos e biológicos; em segundo lugar, a teoria das representações pressupondo que a subjetividade humana é constituída de componentes psicobiológicos e sociais, conseqüentemente, reconhece que são várias as áreas, dentro e fora do campo genérico "psicologia", que podem contribuir para os estudos dos comportamentos e práticas humanas. Parafraseando Lane (2001), entender que toda psicologia é social, não é negar ou supervalorizar uma dada corrente de estudo, em detrimento das áreas afins (sociologia, antropologia, história, e mesmo outras correntes da psicologia), mas tão somente destacar dentro do "universo epistemológico" das pesquisas científicas, um recorte - entre os inúmeros que são possíveis, e, no corrente caso, o psicossocial. ${ }^{8}$ Esse recorte presume, portanto, limites teóricos e analíticos de nossas observações, por isso passíveis de revisão, complementação e mesmo oposição.

8 Enfatizamos a imprescindibilidade da aproximação entre estudos históricos e da psicologia social, para a ampliação da análise de ambas as áreas de conhecimento. Partindo-se da premissa básica do comportamento vivo ou do social vivo, entendemos que, a despeito do período histórico a ser analisado, o uso ampliado das fontes históricas não somente poderá revelar valiosas informações em termos históricos (arcabouço cultural dos grupos e sociedades), mas também psicossociais (alguns porquês dos comportamentos, em dadas épocas) do mesmo objeto. Poesia, música, história oral, aliados aos documentos históricos, tradicionais fontes da disciplina História, podem tornar-se valiosos para a diversificação e o enriquecimento dos estudos representacionais, e, por conseguinte, ratificando a inerente natureza interdisciplinar das produções científicas e humanas (Vieira et al, 1991) e sinalizando uma verdadeira simbiose epistemológica. 
História e psicologia social como áreas complementares de estudo das sociedades humanas, na interseção propiciada pela TRS's, incrementam as análises da transformação sócio-histórica sobre a trajetória da sociedade brasileira, tanto considerando os padrões de comportamento que se vêm reproduzindo, quanto, pari passu, modernizando-se (SELIGMAN, 1995; MARTINS, 1994), e que podem influenciar no processo de ancoragem e objetivação das representações sociais atuais e do imaginário social num todo (SÁ, 1998; 1993).

Tomando-se como pressuposto que as ações sociais são pertencentes a uma complexa rede de imbricações socialmente compartilhadas e transformadas, pensamos que não há razão para pensar as ações dos policiais fora dessa rede de múltiplas influências.

Se, por um lado, segundo Bretas (1999) e Bretas e Poncioni (1999), devido às particularidades de seu ofício (lidar diretamente com a violência e a autoridade de que dispõe) o policial é "naturalmente" suscetível às práticas extrajudiciais (desrespeito das leis, dos direitos humanos, desconfiança em relação aos out-siders) e tenda a adaptar os conteúdos oficiais adquiridos na sua formação, aperfeiçoamento e atualização, às necessidades imediatas durante as operações de trabalho (o abuso de autoridade acontecendo numa relação diretamente proporcional ao nível do medo que sente), por outro lado, Briceño-Léon, Carneiro e Cruz (1998), destacam que setores da população são os principais motivadores das práticas extrajudiciais da polícia. Como vimos, isso ocorre notadamente nos países periféricos (SANTOS, 1997; MACÉ, 1999), o que sempre põe em risco a democracia e o Estado de Direito.

Por essa razão, tomamos a profissionalização não como o meio suficiente para o controle da violência policial. Tendo sido adotado um conceito suficientemente amplo e complexo (MESQUITA NETO, 1999), que leva em conta a influência de interesses sociais no direcionamento das ações policiais, da mesma forma que as características internas da administração 
da polícia, e capaz de caracterizar a violência policial não somente em termos ilegais, ilegítimos e anormais, mas principalmente antiprofissionais, acreditamos ter contribuído para a discussão sobre a gestão democrática, tanto da violência quanto das instituições policiais. Procuramos contribuir para ampliar as formas de se enxergar a violência nos seus vários matizes, aumentando-se as possibilidades de proteção à população, mas em contrapartida, considerando o policial como ser, cidadão e indivíduo, tão frágil quanto outro qualquer, que deve ser devidamente formado, ter chances reais para aperfeiçoar e atualizar seus conhecimentos, de forma a não ser apenas um instrumento para a manutenção do status quo dos grupos no poder.

A identificação da Representação da Profissionalização de Policiais Civis/ES como grave entrave à implementação da democracia no ES, não deve ser justificativa para o imobilismo. Ao contrário, deve ser o marco de novas práticas e comportamentos sociais engajados na implementação de projetos de intervenção pública moralizantes, para a superação das mazelas sociais, e para o reconhecimento do sofrimento ético-político de cada indivíduo, grupo ou classe social. Aqui, enfatizamos, principalmente, a situação do próprio policial considerando a importância, a responsabilidade e os perigos inerentes à sua profissão.

O direito natural de uso da violência há muito não nos pertence e, considerando o crescimento da população mundial, o avanço da tecnologia de guerra e o acirramento das questões ideológico-religiosas, intensificadas pelo processo de globalização da comunicação, o seu retorno poderia significar a nossa rápida ruína. Embora nossas práticas sociais sejam anteriores ao nascimento do Estado, dificilmente poderíamos sobreviver, ou viver mais eqüitativamente, sem a sua mediação (LIPOVETSKY, 1997; WEBER, 1968).

Ratificamos a importância do Estado de Direito, com a sua capacidade de cooptação e gerenciamento da violência legítima, única via de atuação e transformação positiva da sociedade. Verifica-se que a fragmentação e a ineficácia estatal características dos países periféricos (MACÉ, 1999), facili- 
tam a emersão de práticas sociais criminais, principalmente marcadas pelo narcotráfico e contrabando de armas, cujo poder, em muitas situações, abala a soberania das instituições democráticas.

Considerando como eixo central a ação mediadora do Estado de Direito sobre o social, sugerimos, tendo como base as representações identificadas, algumas ações de ordem pública que nos parecem importantes para o avanço e a concretização cotidiana da democracia, principalmente no ES.

Primeiramente, destacamos a cabal importância das pesquisas acadêmicas e da valiosa contribuição que a academia pode fornecer ao Estado, no sentido de sugerir, orientar e retificar as ações públicas, nos vários campos de intervenção. Exemplos dessa contribuição podem ser identificados nos trabaIhos de Cavassani (1998), Bourguignon (1996) e Menandro e Souza (1996), que puderam apontar inúmeros problemas de ordem intelectual, ético-moral e infraestrutural que cercam a profissão policial, dificultando ou mesmo impedindo que os policiais cumpram as suas responsabilidades socioprofissionais.

A adoção de uma perspectiva psicossocial para o entendimento das ações dos policiais, como vimos, é sine qua non para a proteção da população, para a construção de uma imagem positiva do Estado, e principalmente, do profissional-policial-cidadão (MENANDRO; SOUZA, 1996), que poderá vir a ser mais respeitado e apoiado, em vez de, prioritariamente, punido (ADORNO, 1999; MESQUITA NETO, 1999a; 1999b). O investimento do Estado nas universidades, notadamente nas federais em função de sua tradição de pesquisa científica, aliado à facilitação de acesso aos setores envolvidos na elaboração de projetos de intervenção social estatal, pode representar uma eficaz ferramenta para o sucesso das campanhas públicas.

Em segundo lugar, considerando-se as representações dos policiais, entendemos que a estruturação do setor de apoio psicológico e da academia de polícia, não somente viabilizaria a maior integração entre os policiais, mas também incentivaria o seu desenvolvimento físico-intelectual, contribuindo ainda para a construção simbólica de uma instituição organizada, forte e socialmente relevante. 
E, por último, tomando também como referência os resultados encontrados, trataremos de um ponto bastante polêmico e delicado: a dependência política da polícia. A implementação de eleições internas para os cargos de chefia, talvez pudesse viabilizar a maior independência política da polícia em relação aos centros de poder do Estado, representantes das elites conservadoras. A polícia poderia também fazer valer o seu ponto de vista técnico-científico na avaliação dos atos policiais no que se refere à sua legalidade, legitimidade, normalidade e grau de profissionalização (MESQUITA NETO, 1999a; 1999b).

\section{Referências}

ABRIC, J. C. A Abordagem estrutural das representações sociais. In: MOREIRA, A. S. P.; OLIVEIRA, D. C. (Orgs.) Estudos Interdisciplinares de representação social. Goiânia, AB, 1998, p. 27-38.

ADORNO, S. Insegurança versus direitos humanos: entre a lei e a ordem. Tempo Social, USP, São Paulo, n. 11 (2), p. 129-153, fev. 2000.

BOURGUIGNON, D. R. Análise das condições de trabalho e saúde da polícia civil do Espírito Santo: Relatório de Pesquisa. Vitória: FUNDACENTRO, 1996. p.95-113.

BRETAS, M. L. Observações sobre a falência dos modelos policiais. Tempo Social, USP, São Paulo, n. 9 (1), p. 79-94, 1997.

BRETAS, M. L.; PONCIONI, P. A cultura policial e o policial civil carioca. In: PANDOLFI, D. C. et al. (Orgs.). Cidadania, justiça e violência. Rio de Janeiro: Fundação Getúlio Vargas, 1999. p. 149-163.

BRICENÕ-LEÓN, R.; CARNEIRO, L. P.; CRUZ, J. M. O apoio dos cidadãos à ação extrajudicial da polícia no Brasil, em El Salvador e na Venezuela. In: PANDOLFI, D. C. et al. (Orgs.). Cidadania, justiça e violência. Rio de Janeiro: Fundação Getúlio Vargas, 1999. p. 119-127. 
CALLIGARIS, C. Lei e comunidade: algumas propostas. In: PINHEIRO, P. S. et al (Orgs.) São Paulo sem medo. São Paulo: Garamond, 1998. p.59-72.

CARNEIRO, L. P. Para medir a violência. In: PANDOLFI, D. C. et al. (Orgs.). Cidadania, justiça e violência. Rio de Janeiro: Fundação Getúlio Vargas, 1999. p. 165176.

CAVASSANI, S. M. C. A utilização da violência na atividade policial: da insanidade coletiva à loucura solitária. 1998. 173 f. Dissertação (Mestrado em Psicologia) - Programa de Pós-Graduação em Psicologia, Universidade Federal do Espírito Santo, Vitória.

CHAUÍ, M. A não-violência do brasileiro, um mito interessantíssimo. Almanaque: Cadernos de Literatura e Ensaio, Brasiliense, n.11, p. 16-24, 1980.

DEJOURS, C. A Banalização da injustiça social. Rio de Janeiro: Fundação Getúlio Vargas, 1999.

ESPÍRITO Santo (Estado). Polícia Civil. Estatuto do policial civil do Espírito Santo: Lei 3400 de 14 de janeiro de 1981, alterada pela Lei complementar 03 de 19 de janeiro de 1990.

JOVCHELOVITCH, S. Representações sociais: para uma fenomenologia dos saberes sociais. Psicologia \& Sociedade, São Paulo, n. 10 (1), p. 54-68, 1998.

LANE, S. T.M. O que é psicologia social. São Paulo: Brasiliense, 1991.

LANE, S. T.M. A psicologia social e uma nova concepção de homem paraa psicologia. In: LANE, S.T.M.; CODO, W. (Orgs.). Psicologia social: o homem em movimento. São Paulo: Brasiliense, 2001. p.10-19.

LIPOVETSKY, G. A era do vazio: ensaio sobre o individualismo contemporâneo. Lisboa: Antropos, 1986.

MACÉ, E. As formas de violência urbana: uma comparação entre França e Brasil. Tempo Social, USP, São Paulo, n. 11(1), p. 177-188, maio. 1999.

MARTINS, J. S. O poder do atraso: ensaios de sociologia da história lenta. São Paulo: Hucitec, 1994. 
MENANDRO, P. R. M. Um levantamento dos fatores responsáveis pela violência policial. Encontros com a Civilização Brasileira, n.11, p.141-150, 1979.

MENANDRO, P. R.M.; SOUZA, L. O cidadão policial militar e sua visão da relação polícia-sociedade. Psicologia USP, São Paulo, v. 7, n. 1/2, p.133-141, 1996.

MESQUITA NETO, P. Violência policial no Brasil: abordagens teóricas e práticas de controle. In: PANDOLFI, D. C. et al. (Orgs.) Cidadania, justiça e violência. Rio de Janeiro: Fundação Getúlio Vargas, 1999. p.129-147.

MORIN, E. Amor, poesia, sabedoria. Rio de Janeiro: Bertrand Brasil, 1998.

MOSCOVICI, S. A representação social da psicanálise. Rio de Janeiro: Zahar Editores, 1978.

NOvO, H. A. De Tripas e Corações: A Dimensão ético-afetiva na construção de uma cultura da violência. In: TRINDADE, Z. A.; CAMINO, C. (Orgs.) Cognição social e juízo moral. Rio de Janeiro: Associação Nacional de Pesquisa e PósGraduação em Psicologia/ANPEP, 1996. p.15-23.

PORTO, M. S. G. A violência entre a inclusão e a exclusão social. Tempo social, USP, São Paulo, n. 12(1), p. 187-200, maio. 2000.

SÁ, C. P. A Construção do objeto de pesquisa em representações sociais. Rio de Janeiro: UERJ, 1998.

SÁ, C. P. Representações sociais: o conceito e o estado atual da teoria. In: Spink, M. J. (Org.) O conhecimento no cotidiano - as representações sociais na perspectiva da psicologia social. São Paulo: Brasiliense, 1993. p.19-45.

SANTOS, J. T. A arma e a flor: formação da organização policial, consenso e violência. Tempo social, USP, S. Paulo, n. 9(1), p. 155-167, maio. 1997.

SAWAIA, B. B. O sofrimento ético-político como categoria de análise da dialética exclusão/inclusão. In: SAWAIA, B. B. (Org.) As artimanhas da exclusão - análise psicossocial e ética da desigualdade social. São Paulo: Vozes, 1999. p.97-118.

SELIGMAN, M. E. P. O que você pode e o que não pode mudar. Rio de Janeiro: Editora Objetiva, 1995. 
VIEIRA, M. P. A. et al. A pesquisa em história. São Paulo: Ática, 1991.

WAGNER, W. Sócio-gênese e características das representações sociais. In: Moreira, A.S.P. e Oliveira, D.C. (Orgs.) Estudos interdisciplinares de representação social. Goiânia: AB, 1998. p.03-25.

WEBER, M. Ciência e política duas vocações. São Paulo: Cultrix, 1968.

WIEVIORKA, M. O novo paradigma da violência. Tempo social, USP, São Paulo, n. 9(1), p. 5-41, 1997.

Recebido: 03/12/2003

Aceite final: 16/01/2004

\section{Resumo}

O estudo objetivou identificar as representações sociais sobre a profissionalização de policiais civis e suas relações com o incremento e a manutenção do Estado democrático. Foram aplicados questionários semiestruturados a uma amostra de agentes e investigadores de polícia, focalizando a profissionalização nos níveis pessoal, institucional e político. Os elementos representacionais identificados foram: 1) a falta de investimento na instituição; 2) a subserviência da polícia aos interesses de grupos políticos conservadores; 3) a profissionalização como aquisição de conteúdos técnicos que objetivam o ganho pecuniário e a categorização criminal de segmentos socialmente excluídos. O estudo conclui que esses elementos atuam como obstáculos para a implantação e a manutenção do Estado de direito no Espírito Santo.

Palavras-chave: representação social, profissionalização, democracia, polícia civil, controle da violência. 